\title{
Energy Trading Perspectives in the Digital Era
}

\author{
András PUSKÁS-TOMPOS \\ Bucharest University of Economic Studies, Bucharest, Romania \\ apuskas@yahoo.com
}

\begin{abstract}
The aim of the paper research is to identify and improve business models in energy trading by analyzing the current situation and developing scenarios for the evolution of business models in the Digital Era. It is very important to analyze, identify and track those directions that we believe will drive energy trading in order to be able to design and create new sustainable business models. We highlight the possibilities and ways of improving the energy trading, analyzing the rapid evolution of the field, generated by the emergence of several new factors that can influence this industry. Beside those directions at which electricity trading is heading in the Digital Era, the research also describes main innovations in the field such as Smart Grids, Blockchain Technology, Peer-to-peer trading platforms and Demand Response through which the purpose is to attract final consumers to the energy trading on web platforms or mobile applications with which they can properly control their electric appliances and self-generation units in their homes, all these supervised and guided by artificial intelligence. The type of research proposed to identify the current condition and to be able to develop new trading models is empirical research through qualitative analysis. Beyond incentives and monetary benefits, the focus is on final consumer education and increased awareness towards a more conscious, optimal and rational consumption of electricity that can lead to both a better use of the energy production from renewable sources and a reduction of pollutant fossil fuel electricity generation and carbon dioxide emissions without endangering the proper functioning of the electricity systems. Previous researches are based more on incentivizing or penalizing end consumers in present paper, more emphasis is placed on attracting the end consumer to his own electricity trading through mentioned innovation, but also supervised and guided by artificial intelligence.
\end{abstract}

Keywords: energy trading, demand response (DR), smart grid, peer-to-peer (P2P), blockchain, artificial intelligence.

\section{Introduction}

In recent years the evolution of energy trading went through very dynamic development and evolution. Because this product is produced as much as it consumed in a certain moment and because it cannot be stored makes it slightly different commodity from others of the same category.

The European electricity market and trading went through several changes during the years (Busu et al., 2019). European Parliament together with Council of the European Union in order to reach the modern trading of nowadays had to adopt series of law packages. Electricity and gas markets were operating under monopoly regime back in the 90's, they were not liberalized as today. Nowadays companies can transfer the ownership of electricity through Energy Exchanges (on these exchanges are traded mostly financial products but also can offer physical delivery of these products) or Over-the-Counter market. Companies which want to trade physical electricity (not financially) or they are not registered to energy exchange will have to trade physical electricity via over-the-counter-trading or referred also as OTC trading (Murphy, 2019).

The following scheme presents show how developed electricity markets work in the EU. 


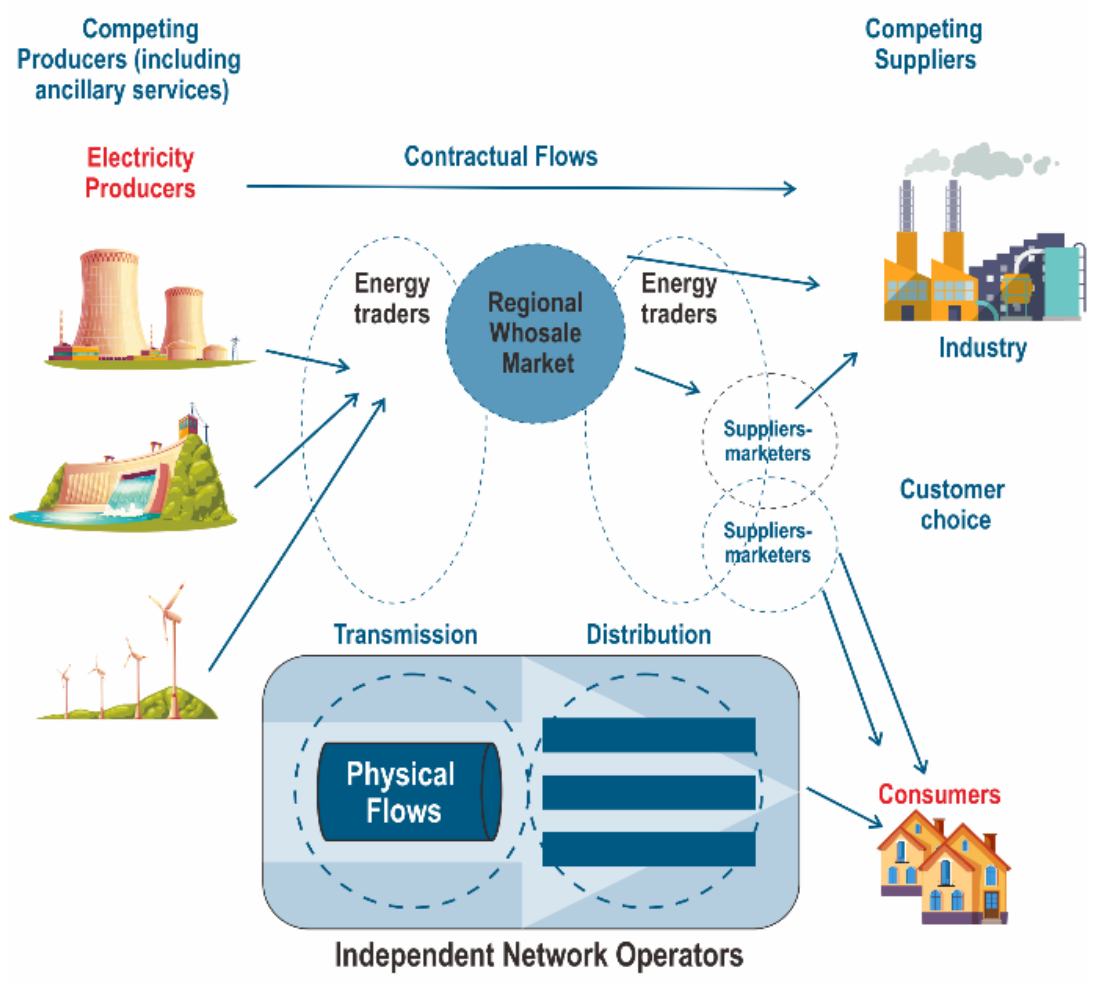

Market Prices OTC and on Power Exchanges

Figure 1. Illustration of the developing EU electricity market

Source: Adapted from The basics of wholesale energy trading, the role of EFET Our vision for further market development, EFET 15 years Edition, 2012, page 4: https://www. efet.org/Files/Documents/Energy\%20Background/Highlights-II-Final.pdf.

An important role is played by electricity exchanges, where the ownership of the goods is transferred between participants. Please find below the scheme which shows how settlement is done on DAM and Derivative Energy Exchanges. 


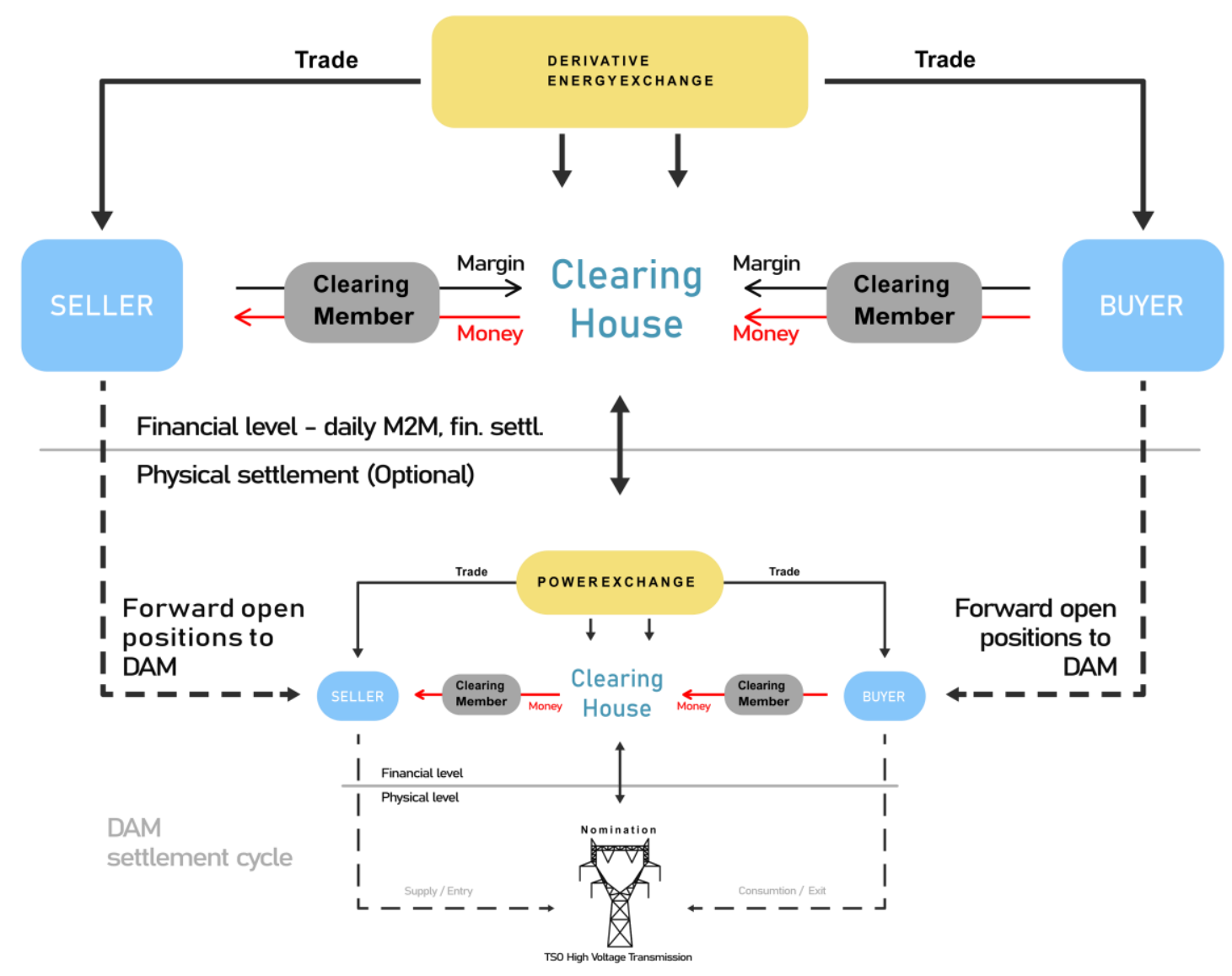

PICBE | 18

Figure 2. Clearing and settlement - Power segment

Source: Adapted from Hungarian Derivative Energy Exchange (HUDEX) webpage https://hudex.hu/en/trading/market-operations/clearing-and-settlement

In order to be able to design and create new sustainable attractive business models it is very important to analyze, identify and track those directions that we obtain within the research carried out and indicate in which direction it is heading the energy trading activity. Demand Response (DR), Smart Grid, Peer-to-Peer (P2P), Blockchain and Artificial Intelligence are the latest trends in the field of energy trading, new technologies that allow electricity Consumers or Prosumers to sell or buy electricity through aggregators on the wholesale electricity market, to trade between them and to obtain some incentives when shifting their electricity consumption.

Through P2P market platforms Prosumers can sell their surplus of their renewable electricity production or buy they needs in the same low-voltage grid. P2P energy trading field is still raw and also research in the matter is still at an early stage, because of this no consensus on what kind of data processing and sharing infrastructure offers the best results and which one is more efficient. Prosumers can access the service of an aggregator to control directly the loads of energy sources even if each household can trade energy with others (also the aggregator can make these deals in the name of the Prosumer). P2P trading platforms in order to process data generated by the households can be centralized (cloud based) or with distributed infrastructure (blockchain based) (Alam et al., 2019). 
Smart grids can be described as the upgrade of traditional electricity delivery systems and also could be observed a trend toward this kind of grid. Traditional electricity delivery systems allow the communication of electricity data on one way while smart grids allow the communication of electricity data on two ways. The biggest advantage of smart grids is that they offer real-time data collection on supply and demand during the distribution process and makes monitoring, generation and supply more efficient (Studentenergy.org website, 2019).

PICBE | 19

Artificial intelligence was adopted by electricity generators and retailers in order to improve their operation. General Electric by using such artificial intelligence applications which correlate weather patterns data with turbine operation can forecast wind power generation with almost a week in advance (Ernst \& Young, 2019).

The electric power sector is facing different kinds of challenges such as high emissions, high energy losses, low efficiency and reliability issues. Because of traditional flat electricity prices, but also because the difference between wholesale electricity market price and retail prices (the way it is made up) provide a route to inefficient usage of resources, because there is no motivation for consumers to adjust their electricity consumption to supply costs. A very efficient strategy for dealing with all the above-mentioned challenges in power systems, is to use demand side management (DSM) programs. Demand Response (DR) can be described as changes in the electricity utilization by end consumers from their usual consumption patterns as a response to electricity price changes over time, but also to receive incentives in order to decrease electricity consumption when electricity is expensive on the wholesale market or the electric network's reliability is jeopardized (Rezaee Jordehi, 2019).

Aforementioned are the reason why innovations, researches and the design of new sustainable business models are needed which attract and maintain end consumers through these newly developed technologies. In the following chapter we will analyze some recent studies about how can be attracted and maintained final consumers to these new business models in energy trading and other trends in matter of energy trading and supply, but also through our research we want to make some improvements to them.

\section{Literature review}

\section{Perspectives of energy trading in the scientific literature}

The number of smart houses is increasing from year to year, P2P trading systems are becoming more efficient and optimal, does not matter if they are centralized (cloud-based) or with distributed infrastructure (blockchain-based), and since these systems become so performants and fast, demand response programs, with the support of artificial intelligence, become quite attractive and easy to participate by prosumers and electricity consumers. Hereafter we have to research and analyze how end consumers could be much better attracted and maintained in these demand response programs.

An interesting research was released about how the modelling of demand response using behavioral economics theory can be improved. Most of the existing works are inclined to use a techno-economic approach because researchers focus on aspects which help them in modelling as it happens to be in this case where it is an economic and technical approach. Classical economic theories assume that decision makers are rational economic actors and also well-informed, in our case of demand response programs they are the electricity consumers or prosumers. Even if the best accessible theory of consumer choice are classical economic theories and also the most acceptable to be assimilated into techno-economic energy system models sometimes this assumption is incorrect. When we are designing business models related to energy interventions 
it is important to consider the characteristics of the behavior of interest. Behavior can be classified in two groups taking into account the main features. The first one can be characterized as affective, fast, effortless, automatic, associative, unconscious and uncontrolled which is referred by the author as routine behavior and the second type as rational, slow, effortful, reflective, rule-based, conscious and controlled is referred as deliberative behavior. Routine behavior can become habitual and it is repetitive, which is why it is influenced by the context in which the decision is taken and also by the subconscious preferences. Deliberative behavior is invoked in response to less frequent and more significant choices. The author suggest that nontechno-economic factors influence energy-related decisions and continues his research based on studies that are built on these types of approaches which understands the outcome of human aspects if such decisions. These points of views can be categorized in two groups like social practice theory (SPT) approach and behavioral economic (BE) approach. Social practice theory highlights that energy consumption is a factor of social practices, to make some social practice which can be washing. Social practices are done almost subconsciously and in most cases are familiar to a person. Because of this for the studies of routine behavior this approach is not the most suitable when creating models about energy-related behavior. Behavioral economic approach is based on microeconomics and psychology in order to integrate consistent, fundamental and consistent biases in individual decision-making. Behavioral economic approach cab be more suitable for researches and studies on deliberative behavior when the focus is on individual decision-making. Because demand response programs require deliberative customer decisions the author suggests that most of the researches in matter should be based on behavioral economic approach. Researches on BE offers evidence that consumers can change predictably and consistently from usual models, if they are well informed and conscious deliberation is also involved. Behavioral economic was investigated in the energy context by engineers, game theorists, management theorists and economists. The most researched problems can be categorized in three groups like investment in energy efficiency, response to variable but predetermined electricity prices and energy trading amongst distributed autonomous agents. Impact of anchoring, loss aversion and status quo were reviewed regarding investments in energy efficiency. Psychological influences and cognitive biases (are systematic patterns of deviation from norm or rationality in judgment) can influence consumers' commitment to variable electricity prices. A trial about how many consumers would like to change the electricity subscription to a three-part tariff from a flat-rate tariff showed that more than $90 \%$ of the participants were loss-averse and would not change (Good, 2019).

Demand response programs will have a great role in the decarbonization of future energy systems. Large scale electrification of transport and heat are foreseen in many future plans which will increase substantially the electricity consumption internationally.

Further we analyze a research which examines 83 demand response schemes (19 from established programs and 64 from trials) from 18 countries as US, several countries in Europe, Australia, Canada, the UAE, Australian and New Zealand (North America 63\% and Europe $30 \%$ ). Further we will summarize the outcomes of the research about factors that can affect engagement and enrolment to demand response programs. Factors that were identified in that may influence of response rates are automation technology and real time information, appliance ownership (level of electricity consumption) and climate, opt-in vs opt-out, price ratio and level of commitment by organizers. The analysis of automation technology and real-time information revealed that responses on demand response when the consumer had additional information as inhome displays presenting price levels, offered result with $2.5 \%$ higher than programs with pricing 
alone. Also, consumers which use automation technologies responded with $15 \%$ more than those with neither technology. Responses from consumers with both automation and additional information were on average 13\% higher than from pricing only. Investigation on appliance ownership and climate revealed that where baseline electrical demand is higher. Consumers which own electric heating and air conditioning than consumers without these larger electrical consuming appliances. Regarding seasonal variations responses were lower in those countries where winter is relatively very cold or where summer is very hot. Observations on the enrolment of consumers recruited opt-in and opt-out showed that the response rate from opt-in recruitment (volunteer participation) was higher than responses from consumers which were recruited through opt-out method. Regarding price ratio the studies outcome showed that the response was higher when price ration between peak price and off-peak price was reasonable, but also revealed that a better response rate can be obtained if price ratio is used together with technologies like as information (with in-home displays) or automation. The level of commitment by organizers, in the research, reflects how persevering and persuasive the organizers were, and how well they managed to attract consumers in different demand response trials and programs (in our study we can translate into the level of commitment by suppliers) (Parrish B. et al., 2019).

Summarizing our analysis on these researches described in this chapter we come to the conclusion that most of existing researches are inclined to use a techno-economic approach. Classical economic theories assume that decision makers are rational economic actors and also well informed. Sometimes is incorrect that classical economic theories are assimilated into techno-economic energy system models. When experts are designing business models related to energy interventions it is important to consider the characteristics of the behavior of interest. Behavior is classified in two groups as routine and deliberative behavior. The author of the research expressed that non-techno-economic factors influence energy-related decisions which can be classified in social practice theory (SPT) approach and behavioral economic (BE) approach. He also suggests that for further research in matter BE approach would be more appropriate. Research on BE offers evidences that consumers can change predictably and consistently from usual models, if they are well informed and conscious deliberation is also involved. Research made in many different fields reviewed that investments in energy efficiency are influenced by the impact of anchoring, loss aversion and status quo, but also cognitive biases and psychology can influence consumers' commitment to variable electricity prices. The results from the trials showed that real-time information and the presence of automation technology, comparable incentives and the ratio between off peak and peak electricity pricing, baseline electrical demand linked to appliance ownership and season influence the average response levels in demand response programs. In addition to these factors, for the trials were true also how consumers were attracted in programs as opt-in and opt-out methods, but also the level of commitment by organizers. Both can be transposed and adopted also for suppliers. The outcome from studies indicates us that at least some residential consumers are willing to participate in different forms of demand response programs.

\section{Methodology}

The main objective is to create new sustainable business models that will attract and maintain final electricity consumers to use these newly developed trending technologies in energy trading and supply.

The research method used in our research is interview with experts from different fields related to energy trading, supply and distribution. The interviewed experts and employees work 
in the energy sector (or related to) and their occupations are analysts, portfolio managers, supply and sale directors, sale agents, advisory to CEO, traders, experts from innovation department, university professors, journalist and also company owners. During interviews in order to guide us we followed a short questionnaire which requires quite extensive detailing of the answers.

In this questionnaire at first we wanted to research, according to experts, that which new technologies would have a bigger impact on energy trading and supply, but also which of these technologies will be much liked by Prosumers and Electricity Consumers, followed by the detailed answers for each question apart. Further we wanted to find out that how end consumers could be attracted in newly designed business models which use these technologies. Related to the complete electrification and decarbonisation of the energy systems through renewable production, we wanted to understand what changes will provide business models and how should be designed by taking into account these tendencies. In what follows we were interested in which type of services should Energy Service Companies furnish to end consumers in order to attract and maintain them. The last question was about how can be integrated smart homes and smart grids with new technologies and how they see the role of these in new business models.

\section{Results and discussions}

The reason why at the moment the consumption is not realized in the most optimal way to neither the industrial consumers nor to the domestic consumers is generated by the fact that price of electricity is cheap. During the transition period to electricity generated from renewable electricity from the actual production made mostly from fossil fuels the price of electricity will increase. Because of this industrial consumers and households will be more rational and they will put more focus on how and when they will consume electricity.

At the first question of our questionnaire we wanted to find out which of the mentioned technologies will have greater impact on energy trading and supply business models. The result was that P2P trading, while an important area, is only one way of optimizing the energy profile of a prosumer. Other options include aggregation, "many-to-many" matching. The regulatory background, definition of a "local energy community" is also necessary. Blockchain has limited perspective in energy trading due to slow speed when handling a large number of transactions, it does not replace a central counterparty as it does not guarantee payment and is hackable. Flexibility will be an increasingly important product to compensate fluctuations in intermittent renewable energy production. Instead of investing in flexible production, the utilization of the flexibility in demand is a "cheaper" option with large potential. What is concerning DR the regulatory background for aggregators should be developed. Aggregators will be able to gather a large number of smaller consumers, operate and market their flexibility. EU directive calls for the creation of DSO (distribution system operators) level flexibility markets. These markets will be an important step to be able to commercialize flexibility. Smart grids, network digitalization (sensors and switches) are essential to identify the optimal operation of the network. It is also important, that this optimized operation can delay large investments in the infrastructure itself. Smart metering is also important to enable the involvements of industrial consumers and households. AI is expected to be used in every sector from weather forecasting through matching algorithms to energy usage optimization. It will be the key to take full advantage of new technologies. As an example, as trading gets closer to real time, human capacities will be insufficient and AI can take care of activities from background necessary for physical and financial settlement. P2P will remain an important part of the trading cycle, especially during the transition period towards full automation but it might be easily replaced by AI and automated 
technology. The ability to actively balance the grid in real time equals lower balancing costs, higher grid security and stronger overall system. It will also result in happier market players, with lower costs and less burden. Smart grid becomes the core of any system, providing real data input, better reaction and improved accuracy over metering data. Automation and AI generated algorithms will better evaluate, asses and take decisions by themselves, according to specific requirements or helping traders to react faster, better evaluate and perform with higher accuracy. According to the respondents the impact of these technologies on energy trading and supply business models can be ordered as follows: DR, Smart Grid, AI, P2P and Blockchain. DR obtained from the total awarded points $24 \%$ and $82 \%$ from the maximum points that it could obtain.

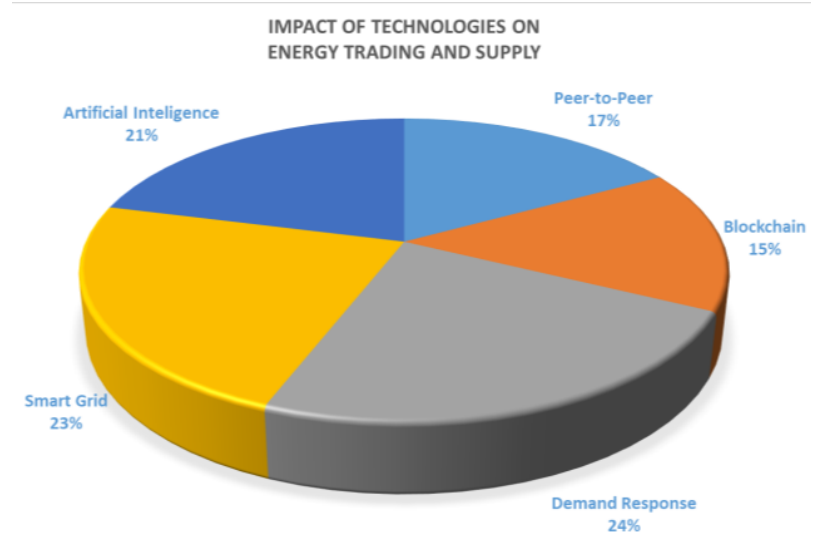

Figure 3. Impact of technologies on energy trading and supply

Source: Authors Own

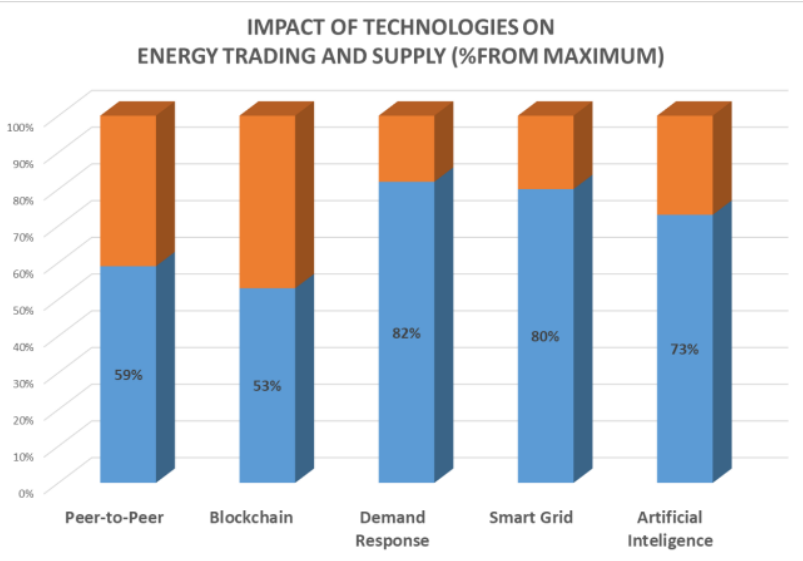

Figure 4. Impact of technologies on energy trading and supply (\% from maximum)

Source: Authors Own

In our second question we wanted to know which technologies will be more attractive to electricity Consumers and Prosumers. As results of the interviews we find out that the most important is not to guess the needs of consumers but to ask and validate them. Consumers, especially if it is a household, will not want to be actively involved in trading or other activities related to electricity with regards to centralized P2P platforms or Blockchain. Consumers may be financially motivated in DR programs and AI technologies can make their lives easier. Overall, the end customers are reluctant to any change and especially to any technology they don't understand. In order to accelerate such adoption, a clear governmental strategy must be defined to show them clear benefits of cost, security and how this will improve their lives. Long-term education, marketing and constant awareness is essential. According to the respondents the attractiveness of these technologies on Prosumers and Electricity Consumers can be ordered as follows: DR, Smart Grid, AI, P2P and Blockchain. DR obtained from the total awarded points $26 \%$ and $84 \%$ from the maximum points that it could obtain. 


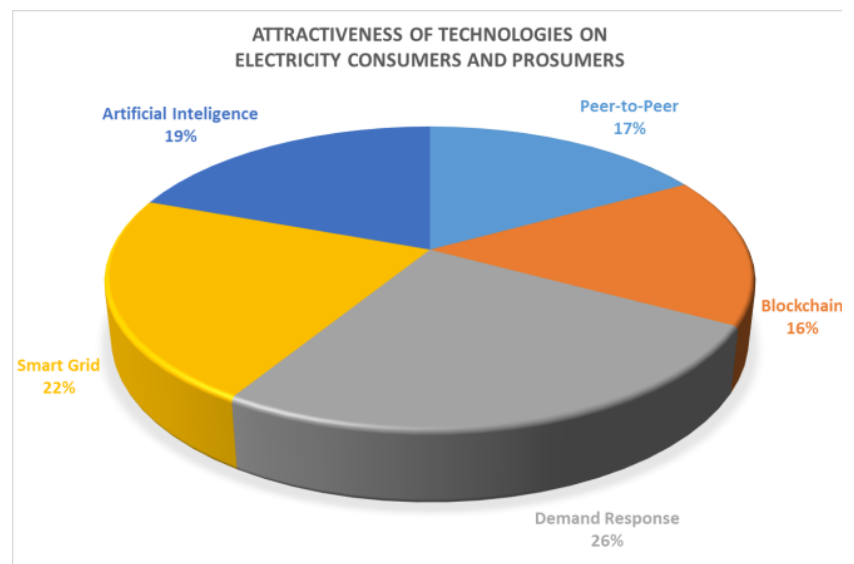

Figure 5. Attractiveness of technologies on electricity consumers and prosumers Source: Authors Own

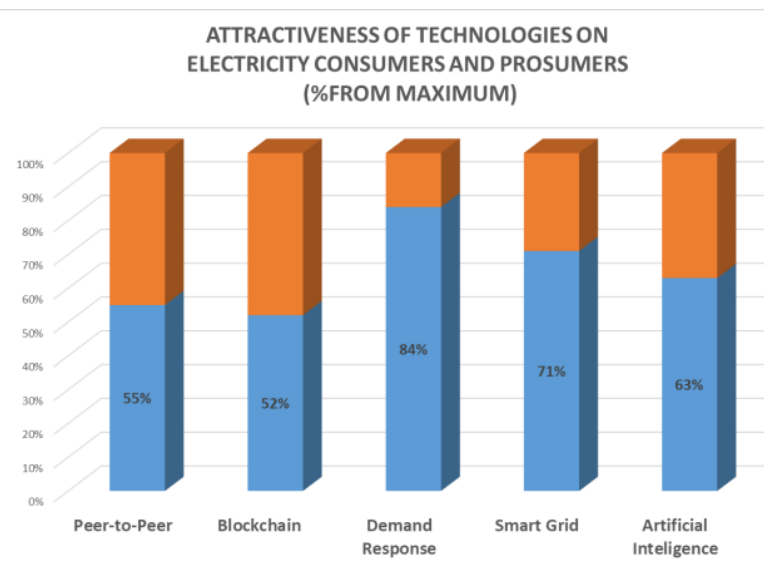

Figure 6. Attractiveness of technologies on electricity consumers and prosumers (\% from maximum)

PICBE | 24

The third question was about how Prosumers and electricity Consumers (industrial or households) could be involved. Results show that dynamic pricing models are the key to influence consumers to change their usage patterns. AI can help to make the processes seamless, whilst smart metering and smart grids are necessary infrastructure elements. Prosumers and consumers are price, effort and time sensitive. If they can cut their costs, save time without much additional effort, these business models could be attractive. Paying a fixed, more-or-less low price for the electricity which they can use any time and in any amount is very comfortable. For them to give up this convenient situation, something must be advantageous.

The fourth question was about if complete electrification and decarbonization using renewable electricity without the mentioned technologies is possible, also how will these affect new business models. The outcome was that is not possible at all and newly created business models should take in consideration this fact. The global energy system is so complex that it cannot be shifted entirely based only on optimizing conventional generation and renewables. Change needs to go along with technology, innovation, optimization and every possible support it can get, especially better energy policies. Optimization and renewables are priorities of any future energy business. Everything needs to be built around these directions impacting the long-term strategy. These technologies are needed and will greatly influence the business models in the near future. Storage systems will evolve very much in the next 10-15 years at the level of consumers (local level) but also at the level of energy system (suppliers and distributors), the role of electricity storing will be also key component.

The fifth question was about what type of services should Energy Service Companies offer in order to attract end consumers to use the mentioned technologies. The outcome shows that ESCOs main role is to install, finance and operate infrastructure elements (solar, wind, storage, consumption optimization, etc.). They can retain consumers through financing and operation, while also developing business models building on the already existing relationship. These can be aggregation, rebate programs or any service or product based on customers' needs. We already observe a diversification of the offered services. ESCOs services do not rely anymore on energy related products only, but on different ones such as telephony, IT\&C, media and cable 
services, appliances, financial services, maintenance services and many more. The added value offered through these additional services will be the main differentiator.

The last question was about what improvements we should make to smart houses and smart grids in order to integrate better with mentioned technologies. The outcome was that homes need to have remotely controlled devices and smart metering. They are regarded as flexibility providers in this sense. Smart grids need to be digitalized (sensors and controllers) to be able to identify network needs at a local level. Dynamic pricing and a DSO level flexibility market needs to be developed where the relevant products can be traded. Internet of Things and Energy of Things are the main two concepts around which any smart home and smart grid need to be built. In order to reach a full integration, system security and integrity is the main driver, flexibility is the second and accessibility and the easiness of use is the third. Soon enough the smart approach will bring better, safer and cheaper experience along the entire value chain and this will force the system to improve and change in order to integrate with the new concepts.

\section{Conclusion}

Lately we noticed that industrial consumers are not only optimizing their energy consumption (electricity and thermal) by inserting centralized systems which control their auxiliary production process within the company cooling, heating, lighting or even water purification, but also control electricity storage and generation from renewable resources. This trend can be observed also through end-consumers who started to thermally insulate newly built houses with more and more efficient materials, to mount storage units or by installing solar panels.

When experts are designing business models related to energy interventions it is important to consider the characteristics of the behavior of interest. Non-techno-economic factors influence energy-related decisions and among them it is recommended that for further research in matter, BE approach would be more appropriate. Research on BE offers evidences that consumers can change predictably and consistently from usual models, if they are well-informed and conscious deliberation is also involved.

In our research we also find out that we have to take in consideration the fact that when we create business that end consumers can be classified as consumers which are price sensitive, consumers which want to have energy independent houses, consumers which want prestige, consumers which have positive attitude towards the environment and consumers which are opened to use newly innovated gadgets, it can be a way of how we approach the client. From our research we can conclude that DR will have a greater impact on energy trading and supply business models and will be more attractive to prosumers and electricity consumers. Previous research shows that attendance to DR programs can be increased by automation technology and real time information, appliance ownership and climate, attracting the consumer via opt-in method (is not excluded neither opt-out method and incentives possibilities are presented gradually), price ratio and level of commitment by suppliers.

In newly built business models we have to communicate and make consumers understand that by using the mentioned technologies and through their active participation to these programs green energy is consumed rationally and optimally and this is the way how can be stopped the global warming and how can be reduced electricity generation from fossil polluting fuels. Beyond these monetary benefits and incentives the center of attention is on final consumer education and increased awareness towards a more optimal, conscious and rational consumption of electricity generated from renewable sources and without endangering the proper functioning of the electricity systems. Greater attention has to be given to Business Model Innovation in 
Energy Trading in the context of market liberalization and moreover to the latest trends in the energy related sectors, as Blockchain, P2P, Smart Grid, DR and AI technologies, but also to storage systems which are gaining more and more importance, technologies which enable prosumers or consumers to sell or buy in real-time electricity through aggregators on the wholesale electricity market or with each other.

The energy poverty and the lack of general education remain a big obstacle against a fast

PICBE $\mid 26$ integration. Government policies need to carefully evaluate this and integrate it in a long-term strategy with real-life solutions.

The conclusion is that we have to involve and attract further end consumers to these programs in order to reach emissions reduction to zero and to reach total electrification from renewable energy. It is important to attract both everyone who makes consumption management decisions regarding from households to larger electricity consuming factories.

\section{References}

Alam M. R., St-Hilaire M., Kunza T., Peer-to-peer energy trading among smart homes, Applied Energy, Volume 238, 15 March 2019, Pages 1434-1443.

Busu, M., Clodnitchi, R., \& Muresan, M.L. (2019). A correlation analysis of the spot market prices of the Romanian electricity sector. Management \& Marketing - Challenges for the Knowledge Economy, 14(1), 150-162.

Chaudhary R., Jindal A., Aujla G. S., Aggarwal S., Kumar N., Choo K. R., BEST: Blockchainbased secure energy trading in SDN-enabled intelligent transportation system, Computers \& Security, Volume 85, August 2019, Pages 288-299.

Laclau B. (July 3, 2019), Ernst \& Young, "As the countdown to a new energy world intensifies, who will beat the clock", https://www.ey.com/en gl/power-utilities/as-the-countdown-toa-new-energy-world-intensifies-who-will-beat-the-clock.

Drăghici M. (July 15, 2019), Ernst \& Young Romania, "Decarbonizarea, digitalizarea și descentralizarea accelerează evoluţia spre o lume nouă a energiei": https://www.eyromania.ro/studii-and-articole/decarbonizarea-digitalizarea-idescentralizarea-accelereaz-evoluia-spre-o-lume-nou-a-energiei/.

EFET, Illustration of the developing EU electricity market, Adapted from The basics of wholesale energy trading, The role of EFET, Our vision for further market development, EFET 15 years Edition, 2012, page 4: https://www.efet.org/Files/Documents/Energy\%20Background/Highlights-II-Final.pdf, accessed on 15th of July, 2019.

European Commission, Energy, Third energy package, accessed on 15th of November, 2019, https:/ec.europa.eu/energy/en/topics/markets-and-consumers/market-legislation/thirdenergy-package

Good N., Using behavioral economic theory in modelling of demand response, Applied Energy Journal, Volume 239, 1 April 2019, Pages 107-116.

Gouardères F., European Parliament, Fact Sheets on the European Union, June 2019, http://www.europarl.europa.eu/factsheets/en/sheet/45/ internal-energy-market, accessed on 25 th of November, 2019.

Hayes B. P., Thakur S., Breslin J. G., Co-simulation of electricity distribution networks and peer to peer energy trading platforms, International Journal of Electrical Power \& Energy Systems, Volume 115, February 2020, 105419.

HUDEX Hungarian Derivative Energy Exchange, Clearing and settlement, Power segment, https://hudex.hu/en/trading/market-operations/clearing-and-settlement, accessed on $20^{\text {th }}$ of January, 2019. 
Nie P., Chen Z., Wang C., Chen X., Innovation analysis under trading energy efficiency, Energy, Volume 186, 1 November 2019, 115866.

Okur Ö, Voulis N, Heijnen P., Lukszo Z., Aggregator-mediated demand response: Minimizing imbalances caused by uncertainty of solar generation, Volume 247, 1 August 2019, Pages 426-437.

O’Raghallaigh F., Stibbs J., Raus L., Kolax M., Blockchain’s Impact On Energy Trading, Market Insight, January 2018, ICIS.

PICBE $\mid 27$

Parrish B., Gross R., Heptonstall Ph., On demand: Can demand response live up to expectations in managing electricity systems?, Energy Research \& Social Science Journal, Volume 51, May 2019, Pages 107-118.

Rezaee Jordehi A. (2019), Optimisation of demand response in electric power systems, a review, Renewable and Sustainable Energy Reviews Journal, Volume 103, 308-319.

Studentenergy.org, Smart Grid, https https:/www.studentenergy.org/topics/smart-grid, accessed on 28th of December, 2019.

U.S. Department of Energy, "What is the Smart Grid?," https://www.smartgrid.gov/the smart grid/smart grid.html, accessed on 15 th of November, 2019.

Vogt G., P2P electricity market platforms, published on January 17, 2018, https://www.linkedin.com/pulse/p2p-electricity-market-platforms-georg-vogt/, accessed on on15th of November, 2019.

Zhang C., Wu J., Zhou Y., Cheng M., Long C., Peer-to-Peer energy trading in a Microgrid, Applied Energy, Volume 220, 15 June 2018, Pages 1-12.

Zeren F., Akkuş H. T., The relationship between renewable energy consumption and trade openness: New evidence from emerging economies, Renewable Energy, Volume 147, Part 1, March 2020, Pages 322-329. 